\title{
Cyclic Voltammetric Study of the Interaction of Biologically Important Metal Ion with Proton Pump Inhibitors
}

\author{
Milton C. Das, Rajib Biswas, Humaiara Akter, M. A. Haque, P. K. Bakshi and A. A. Shaikh* \\ Department of Chemistry, Dhaka University, Dhaka 1000, Bangladesh \\ (Received: 18 May 2015; Accepted: 15 August 2015)
}

\begin{abstract}
Electrochemical studies on the interaction of Fe(III) with proton pump inhibitors (PPIs) (omeprazole, pantoprazole, esomeprazole and rabeprazole) in acetate buffer solution were carried out at gassy carbon electrode (GCE) at various pH (3.5, 4.0 and 4.5). In presence of omeprazole (Ome), the anodic and cathodic peak current for Fe(III) decreased in comparison to solely Fe(III). However, in some cases both the peaks were almost disappeared. Moreover, anodic and cathodic peaks shifted significantly towards negative potential. This is an indication that a strong interaction occurred between Fe(III) and Ome. The maximum interaction is found at 1:2 molar ratio of Fe(III) and Ome at above mentioned $\mathrm{pH}$. The electrochemical interaction of Fe(III) and other PPIs was found as identical with the behavior of Ome. The electrochemical study of the interactions between metal ions and PPIs would provide important information for the technological application of PPIs in human body.
\end{abstract}

Keywords: Proton pump inhibitors, Metal ion, Cyclic voltammetry, Glassy carbon electrode

\section{Introduction}

Proton pump inhibitors (PPIs) are used extensively for the treatment of gastric acid-related disorders because they produce a greater degree and longer duration of gastric acid suppression and, thus, better healing rates, than histamine $\mathrm{H}_{2}$ receptor antagonists ${ }^{1-4}$. PPIs are the most potent inhibitors of gastric acid secretion, with a potential to increase intragastric $\mathrm{pH}$ by several units, as well as hydrogen ion concentration by several hundred to thousand fold $^{5}$. Their mechanism of action involves inhibition of the $\mathrm{H}^{+} / \mathrm{K}^{+}$ATPase enzyme which is presenting gastric mucosal parietal cells. This enzyme is responsible for hydrogen ion secretion in exchange for potassium ions in the gastric lumen ${ }^{6}$. As a result, PPIs can modify the bioavailability and absorption of essential vitamins and minerals both in the stomach and duodenum, which may also affect more distal absorption. Proton pump inhibitors act by irreversibly blocking the hydrogen/potassium adenosine triphosphatase enzyme system of the gastric parietal cells ${ }^{7}$. The proton pump is the terminal stage in gastric acid secretion, being directly responsible for secreting $\mathrm{H}^{+}$ions into the gastric lumen, making it an ideal target for inhibiting acid secretion.

Several transition elements are important to the chemistry of living systems, the most familiar examples being iron, cobalt, copper, and molybdenum. Most of the first row transition metals are important for enzymes ${ }^{8}$. They have one or both of two important properties: (i) some readily change oxidation state, (ii) acting as critical redox couples. Iron is by far the most widespread and important transition metal that has a function in living systems; proteins containing iron participate in two main processes, oxygen transport and electron transfer reactions ${ }^{9}$. They are biologically important and can form complexes with different ligands. Simple chemical interaction of $\mathrm{Fe}$ (III) and other metal ions with PPIs has also been rarely carried out elsewhere ${ }^{10-12}$.

Cyclic voltammetric method has been chosen for this present study because of its potential ability in investigating the redox behavior of electroactive species. The cyclic voltammetric study of various metal ions in presence of ligand has been investigated in our laboratory and reported in detail ${ }^{13,14}$. We have therefore, started a wide ranging electrochemical studies of metal complexes of PPIs using cyclic voltammetry. Here we report a study of cyclic voltammetric redox behavior of transition metal ion, Fe(III) and its interaction with PPIs such as Omeprazole (Ome), Pantoprazole (Pan), Esomeprazole (Eso) and Rabeprazole $(\mathrm{Rab})$ in acetate buffer solution at various $\mathrm{pH}$.

\section{Experimental}

\section{Material and Methods}

Analar grade Iron(III) perchlorate hexahydrate was purchased from Sigma Aldrich and used without further purification. Analytical grade omeprazole powder, pantoprazole sodium powder, esomeprazole magnesium powder, and rabeprazole sodium powder (all PPIs from Sigma Aldrich) were used in this study. Potassium chloride was purchased from BDH, England. For the preparation of acetate buffer solution, extra pure acetic acid (BDH England) and sodium acetate (Merck Germany) were used for maintaining the $\mathrm{pH}$ of the solution. All aqueous solutions were prepared in deionized water obtained from Milli-Q water purification system. The experiments were carried out at room temperature.

\section{Equipments}

A three electrode electrochemical system consists of glassy carbon electrode as working electrode, $\mathrm{Ag} / \mathrm{AgCl}$ (satd. $\mathrm{KCl}$ ) as reference electrode and platinum wire as counter electrode was used. Cyclic voltammetric measurement was performed using computerized electrochemical system, Model CHI 620D, Electrochemical Workstation by CHI Inc., USA. Solution $\mathrm{pH}$ was measured by $\mathrm{pH}$ meter- Metller Toledo, Germany.

\section{Preparation of Stock Solution}

The buffer used in this study was acetate buffer which is prepared by mixing requisite volume $0.1 \mathrm{M} \mathrm{CH}_{3} \mathrm{COONa}$.

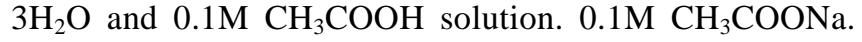
$3 \mathrm{H}_{2} \mathrm{O}$ and $0.1 \mathrm{M} \mathrm{CH}_{3} \mathrm{COOH}$ solutions were prepared using

\footnotetext{
*Author for correspondence. e-mail: aftabshaikh@du.ac.bd
} 
$50 \%$ ethanol-water mixer individually. Stock solution of $1.0 \mathrm{mM} \mathrm{Fe}(\mathrm{III})$ was prepared with analytical grade of respective salt with acetate buffer solution. $1.0 \mathrm{mM}$, $2.0 \mathrm{mM}, 3.0 \mathrm{mM}$, and $4.0 \mathrm{mM}$ solutions of omeprazole, pantoprazole sodium, esomeprazole magnesium and rabeprazole sodium were prepared by using acetate buffer solution. The metal-ligand solutions for complex reaction were prepared by adding identical volume of metal and ligand solution to get $1: 1,1: 2,1: 3$ and $1: 4$ ratios at desired $\mathrm{pH}$.

\section{Preparation of Working Electrode}

This electrode preparation includes the polishing and conditioning of the electrode. At the beginning of each experiment, the working electrode was polished with alumina slurry on the surface of water resistant polishing cloth. Then it was rinsed with plenty of de-ionized water and the whitish alumina was wiped off with a clean tissue paper.

\section{Results and Discussion}

Electrochemical redox behavior of Fe(III) in acetate buffer solution and their interaction with PPIs such as omeprazole, pantoprazole, esomeprazole and rabeprazole were performed at GCE at various molar ratio and different scan rate. The effect of $\mathrm{pH}(3.5,4.0$ and 4.5) in acetate buffer solution was also examined in this study.

\section{Cyclic Voltammetric Investigation of Fe(III) and Its Interac- tion with PPIs}

Cyclic voltammetric studies of Fe(III) in acetate buffer solution: Cyclic voltammetric study of $1.0 \mathrm{mM} \mathrm{Fe}(\mathrm{III})$ in acetate buffer solution at different $\mathrm{pH}$ value was investigated at GCE within the potential window of +1000 to $-800 \mathrm{mV}$. Fig. 1(a) shows a $\mathrm{CV}$ of $1.0 \mathrm{mM} \mathrm{Fe(III)} \mathrm{in}$ acetate buffer solution with scan rate of $100 \mathrm{mVs}^{-1}$ at $\mathrm{pH}$ 4.0. In the forward scan a cathodic peak, $\mathrm{i}_{\mathrm{pc}}$ at about -78.1 $\mathrm{mV}$ and in the reverse scan an anodic peak, $i_{\mathrm{pa}}$ at about $511.9 \mathrm{mV}$ were observed. The cathodic peak results from the reduction of $\mathrm{Fe}(\mathrm{III})$ to $\mathrm{Fe}(\mathrm{II})$, and the anodic peak is for the oxidation of $\mathrm{Fe}(\mathrm{II})$ to $\mathrm{Fe}(\mathrm{III})$. The above result suggests that at $\mathrm{pH} 4.0 \mathrm{Fe}(\mathrm{III})$ undergoes one electron transfer redox reaction. The possible mechanism of the redox reaction is as follows:

$$
\begin{aligned}
& \text { For reduction half-reaction: } \mathrm{Fe}(\mathrm{III})+\mathrm{e}^{-} \rightarrow \mathrm{Fe}(\mathrm{II}) \\
& \text { For oxidation half-reaction: } \mathrm{Fe}(\mathrm{II}) \rightarrow \mathrm{Fe}(\mathrm{III})+\mathrm{e}^{-}
\end{aligned}
$$

Effect of scan rate: The effect of the scan rate on the electrochemical response of $\mathrm{Fe}(\mathrm{III})$ under the identical condition (1.0 mM Fe(III) at $\mathrm{pH} 4.0)$ was examined by taking the cyclic voltammograms of $\mathrm{Fe}$ (III) with scan rate of $50,75,100,125,150 \mathrm{mVs}^{-1}$ as shown in Fig. 1(b). With the increasing of scan rate, the cathodic and anodic peak current increased. The observation suggests that the electrode process is diffusion controlled in acetate buffer medium. The ratio of the oxidation peak current and its corresponding reduction counterpart $i_{p a} / i_{p c}$ is about $0.305-0.498$. It is found that the peak current ratio is decreased with the increasing of scan rate. Also the peak potential separation, $\Delta \mathrm{E}_{\mathrm{p}}$ is in between $536.1-628.1 \mathrm{mV}$. It is increased with the variation of scan rate. These suggest that the redox process is quasi- reversible reaction rather than a reversible reaction. Moreover, the shifting of the peak potential at various scan rates indicates quasi-reversibility of the redox process, which is also characterized by the shape and separation of the cathodic and anodic peak.
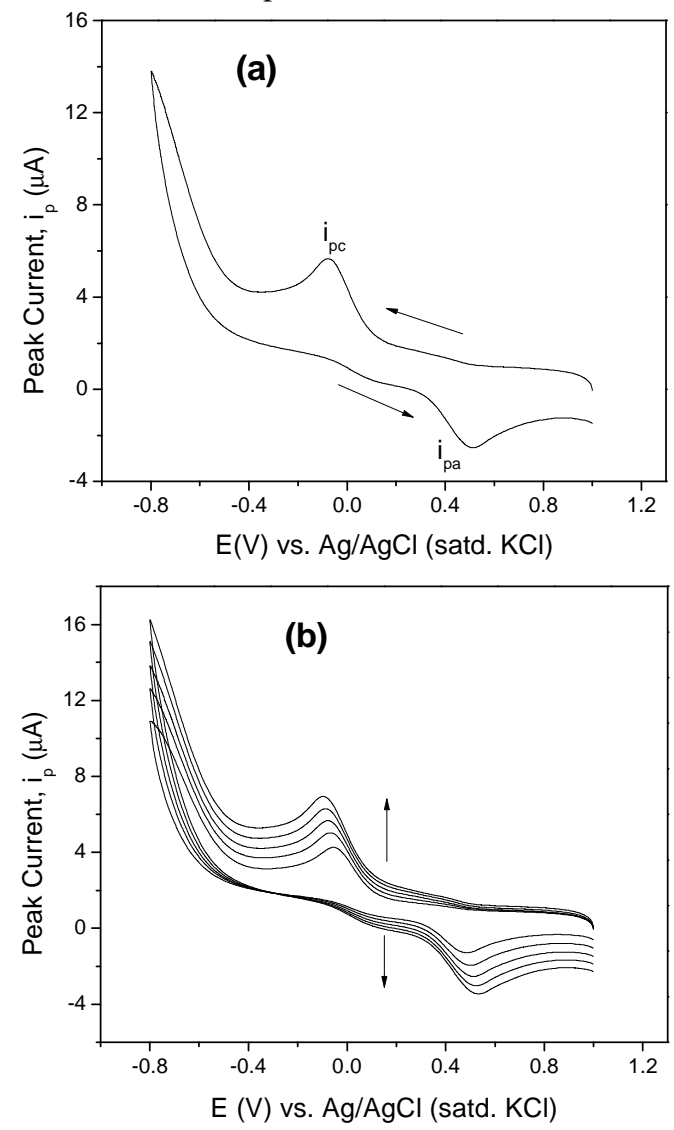

Fig. 1. $\mathrm{CV}$ of (a) $1.0 \mathrm{mM} \mathrm{Fe}$ (III) in acetate buffer solution at $\mathrm{pH}$ 4.0 with scan rate of $100 \mathrm{mVs}^{-1}$ and (b) CVs of $1.0 \mathrm{mM} \mathrm{Fe}$ (III) at various scan rate: $50,75,100,125$ and $150 \mathrm{mVs}^{-1}$ at GCE.

In Fig. 2(a), it is apparent that the peak current for the electrochemical redox reaction of $\mathrm{Fe}$ (III) has linear relation with square root of scan rate. This observation is again in favor of the fact that the electrode process is diffusion controlled. The ratio of the oxidation peak current and its corresponding reduction counterpart has a linear relation with scan rate (Fig. 2(b)). Also the peak potential separation, $\Delta \mathrm{E}_{\mathrm{p}}$ is linearly increased with scan rate (Fig. 2(c)). These results suggest that the redox process is quasi-reversible reaction rather than a reversible reaction.

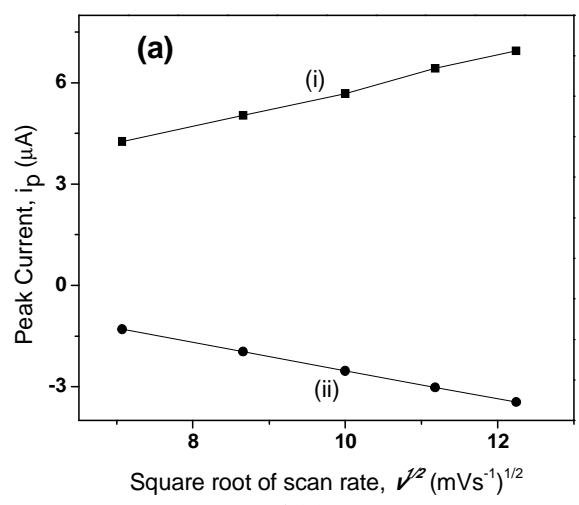

2(a) 

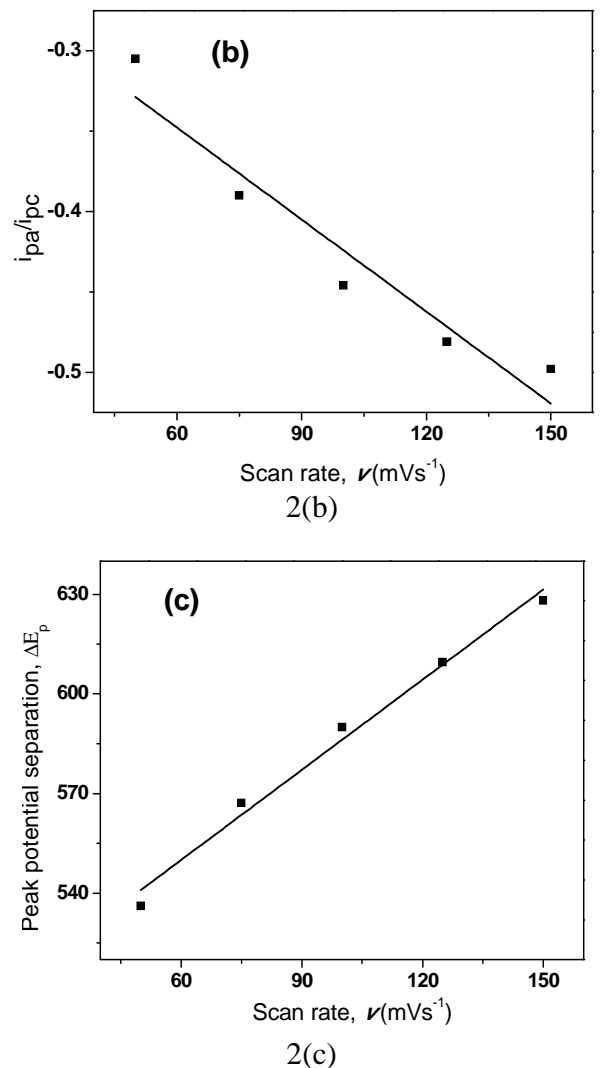

Fig. 2. (a) Plots of cathodic peak current (i) and anodic peak current (ii) as a function of square root of scan rate, (b) Peak current ratio $\left(\mathrm{i}_{\mathrm{pa}} / \mathrm{i}_{\mathrm{pc}}\right)$ dependence on scan rate and (c) A plot of peak potential separation with scan rate for $1.0 \mathrm{mM} \mathrm{Fe}(\mathrm{III})$ at $\mathrm{pH}$ 4.0.
Effect of $\mathrm{pH}$ on the cyclic voltammograms of $\mathrm{Fe}(\mathrm{III})$ : The effect of $\mathrm{pH}(\mathrm{pH} \mathrm{3.5,4.0}$ and 4.5) on the CVs of the redox reaction of $\mathrm{Fe}$ (III) in acetate buffer solution has been investigated as shown in Fig. 3. It is found that with the increase of $\mathrm{pH}$ a distinguishable cathodic peak and intense anodic peak with larger peak height were found. The data from the voltammograms are shown in Table 1.

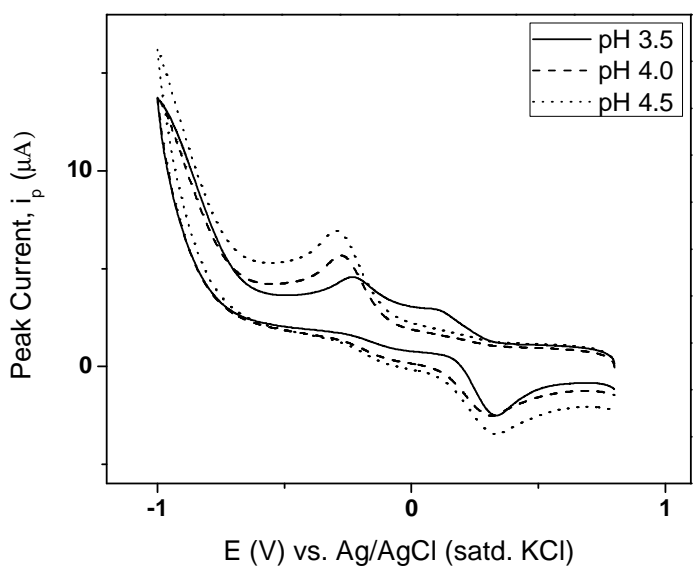

Fig. 3. $\mathrm{CVs}$ of $1.0 \mathrm{mM} \mathrm{Fe}(\mathrm{III})$ in acetate buffer solution at $\mathrm{pH}$ (a) 3.5 (solid), (b) 4.0 (dot-dashed) and (c) 4.5 (dotted).

Table 1. Data obtained from the voltammograms of $\mathrm{Fe}(\mathrm{III})$ at different $\mathrm{pH}$.

\begin{tabular}{cccccc}
\hline Solution $\mathrm{pH}$ & $\mathrm{i}_{\mathrm{pc}}(\mu \mathrm{A})$ & $\mathrm{i}_{\mathrm{pa}}(\mu \mathrm{A})(-)$ & $\mathrm{E}_{\mathrm{pc}}(\mathrm{mV})(-)$ & $\mathrm{E}_{\mathrm{pa}}(\mathrm{mV})$ & $\Delta \mathrm{E}_{\mathrm{p}}(\mathrm{mV})$ \\
\hline 3.5 & 4.570 & 2.520 & 29.3 & 532.1 & 561.4 \\
4.0 & 5.670 & 2.541 & 78.3 & 513.6 & 591.9 \\
4.5 & 6.923 & 3.453 & 96.2 & 530.3 & 626.5 \\
\hline
\end{tabular}

Cyclic voltammetric response of PPIs: Cyclic voltammetric response of Ome, Pan, Eso and Rab were recorded in acetate buffer solution in identical condition as for metal ions. In this condition except Ome and Rab, PPIs showed no significant peak. For Ome a cathodic peak at $-414 \mathrm{mV}$ and an anodic peak at $211 \mathrm{mV}$, and for Rab a cathodic peak at $481 \mathrm{mV}$ has been observed.

Cyclic voltammetric studies of $\mathrm{Fe}(\mathrm{III})$ in presence of omeprazole: The electrochemical study of the interaction of $\mathrm{Fe}$ (III) with Ome in acetate buffer solution at $\mathrm{pH} 3.5,4.0$ and 4.5 has been studied. The CVs recorded for Fe(III), and $\mathrm{Fe}(\mathrm{III})$ in presence of various molar concentrations of Ome (molar ratios of $\mathrm{Fe}(\mathrm{III}) / \mathrm{Ome} ; 1: 1,1: 2,1: 3$ and 1:4) are shown in Fig. 4. The CV recorded for each ratio of Fe(III) and Ome, the peak current for both anodic and cathodic peak decreases than those for solely Fe(III). Moreover, it is apparently found that the cathodic peaks are slightly shifted towards negative direction $(1: 3$ and $1: 4)$ however; it was disappeared for 1: 1 and 1:2; while the anodic peaks are almost disappeared for all ratios at $\mathrm{pH} 3.5$. With the increase of Ome concentration the cathodic and anodic peaks were significantly appeared and shifted towards negative direction. From the data analysis it was found that there is a strong interaction between $\mathrm{Fe}(\mathrm{III})$ and Ome, and the maximum interaction was occurred at 1:2 ratio of metal ion and Ome at this $\mathrm{pH}$.

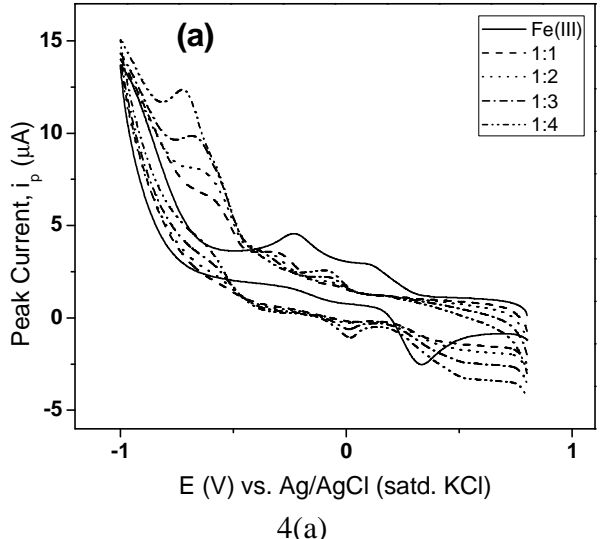

4(a) 


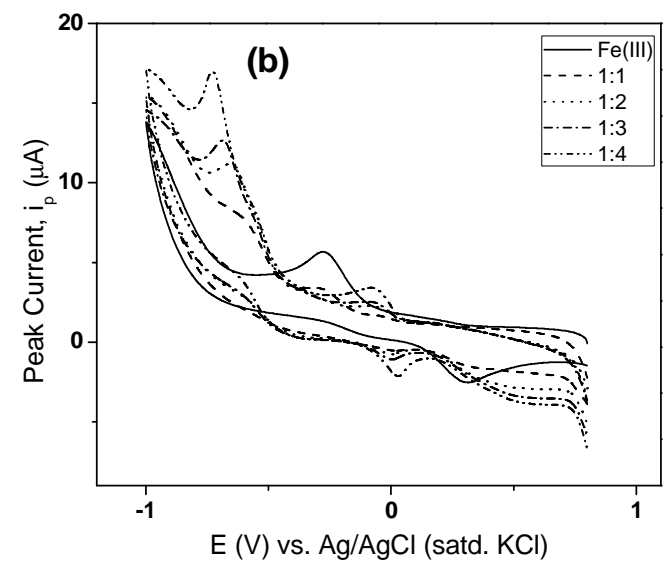

4(b)

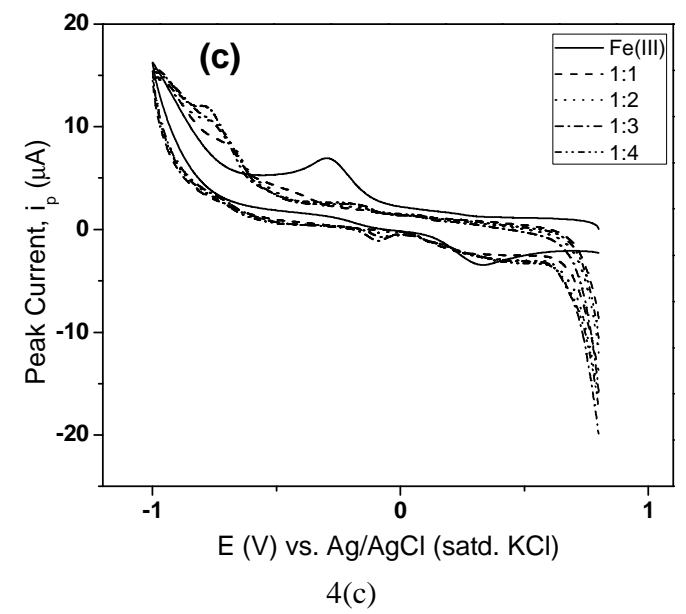

Fig. 4. $\mathrm{CV}$ s of $\mathrm{Fe}(\mathrm{III})$ (solid), and $\mathrm{Fe}(\mathrm{III}) / \mathrm{Ome}$ with different ratio (i) 1:1 (dot-dashed), (c) 1:2 (dotted), (d) 1:3 (long-dashed), and (e) 1:4 (medium-dashed) in acetate buffer solution at (a) $\mathrm{pH} 3.5$, (b) $\mathrm{pH} 4.0$ and (c) $\mathrm{pH} 4.5$.

Similar behavior was also observed in the interaction of $\mathrm{Fe}(\mathrm{III})$ and Ome at $\mathrm{pH} 4.0$ and 4.5. However, at $\mathrm{pH} 4.5$ both cathodic and anodic peaks are almost disappeared at all ratios of metal ions and Ome. In these $\mathrm{pH}$ (4.0 and 4.5) maximum interactions were found at the metal ion and Ome ratio of 1:2. In more acidic medium ( $\mathrm{pH} 3.5$ and 4.0) Ome showed large peak current compared to less acidic medium this is because in more acidic medium the protonation of Ome is facilitated than in less acidic medium ${ }^{7}$.

Cyclic voltammetric studies of $\mathrm{Fe}(\mathrm{III})$ in presence of pantoprazole: The electrochemical study of the interaction of Fe(III) with Pan in acetate buffer at $\mathrm{pH} 3.5,4.0$ and 4.5 has been carried out. The CVs recorded for Fe(III), and $\mathrm{Fe}$ (III) in presence of various molar concentrations of Pan are shown in Fig. 5. The $\mathrm{CV}$ recorded for each ratio of $\mathrm{Fe}(\mathrm{III})$ and Pan, the peak current for both anodic and cathodic peak decreases than those for free $\mathrm{Fe}(\mathrm{III})$. Moreover it is apparently found that the anodic peak is disappeared in all $\mathrm{pH}$; while the cathodic peak is in some cases (1:3 and 1:4) shifted towards negative direction and in other cases (1:1 and 1:2) disapproved. The results suggest that there is a strong interaction between Fe(III) and Pan. It is obvious that a strong interaction occurs at 1:2 molar ratio of $\mathrm{Fe}$ (III) and Pan for all three $\mathrm{pH}$, since both the peak are disappeared at this molar ratio.
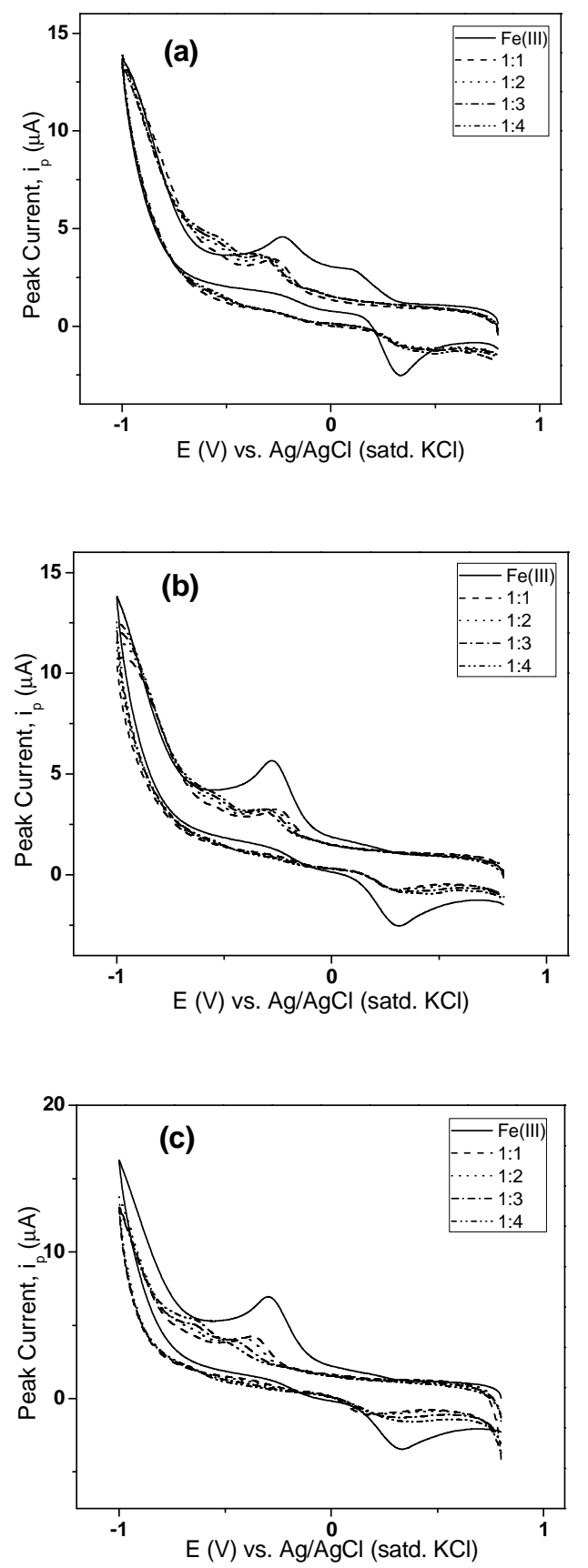

Fig. 5. $\mathrm{CV}$ s of $\mathrm{Fe}(\mathrm{III})$ (solid), and $\mathrm{Fe}(\mathrm{III}) / \mathrm{Pan}$ with different ratio (i) 1:1 (dot-dashed), (ii) 1:2 (dotted), (iii) 1:3 (long-dashed), and (iv) 1:4 (medium-dashed) in acetate buffer solution at (a) $\mathrm{pH} 3.5$, (b) $\mathrm{pH} 4.0$ and (c) $\mathrm{pH} 4.5$.

Cyclic voltammetric studies of $\mathrm{Fe}(\mathrm{III})$ in presence of esomeprazole: The voltammetric investigation of the interaction of $\mathrm{Fe}(\mathrm{III})$ with Eso in acetate buffer at various $\mathrm{pH} 3.5,4.0$ and 4.5 has been carried out. The CVs recorded for $\mathrm{Fe}(\mathrm{III})$, and $\mathrm{Fe}(\mathrm{III})$ in presence of various molar concentrations of Eso are shown in Fig. 6. For each ratio of $\mathrm{Fe}(\mathrm{III})$ and Eso, it is apparently found from the CVs that the cathodic and anodic peaks are disappeared in all ratio of $\mathrm{Fe}(\mathrm{III}) /$ Eso. In more acidic medium (pH 3.5 and 4.0) the Eso 
contributing to the faradic current therefore, a cathodic and anodic peaks was found and it was more pronounced at higher concentration of Eso while at higher $\mathrm{pH}$ the contribution of Eso is negligible to the faradic current. The results suggest that there is an interaction between $\mathrm{Fe}(\mathrm{III})$ and Eso and strong interaction occurred at 1:2 molar ratio.
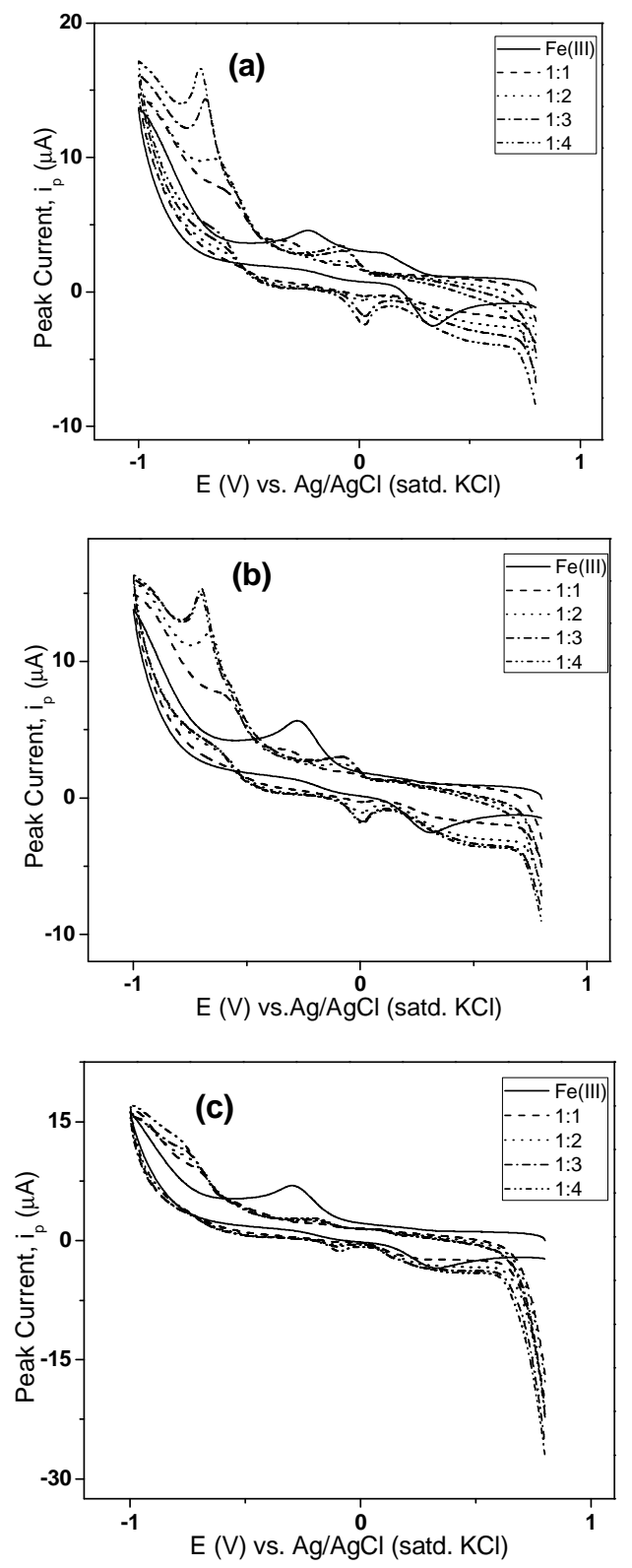

Fig. 6. CVs of $\mathrm{Fe}(\mathrm{III})$ (solid), and $\mathrm{Fe}(\mathrm{III}) /$ Eso with different molar ratio (i) 1:1 (dot-dashed), (ii) 1:2 (dotted), (iii) 1:3 (long-dashed), and (iv) $1: 4$ (medium-dashed) in acetate buffer solution at (a) $\mathrm{pH}$ 3.5 , (b) $\mathrm{pH} 4.0$ and (c) $\mathrm{pH} 4.5$.

Cyclic voltammetric studies of $\mathrm{Fe}(\mathrm{III})$ in presence of rabeprazole: The electrochemical study of the interaction of $\mathrm{Fe}$ (III) with $\mathrm{Rab}$ in acetate buffer at $\mathrm{pH} 3.5,4.0$ and 4.5 has been investigated. The CVs recorded for Fe(III), and Fe(III) in presence of various molar concentrations of Rab are shown in Fig. 7. The CV recorded for each ratio of Fe(III) and Rab, the peak current for both anodic and cathodic peak decreases than those for free Fe(III). Moreover, it is apparently found that a larger cathodic and an anodic peaks was appeared, these peaks are due to the Rab. The results suggest that there is an interaction between Fe(III) and Rab and maximum interaction occurred at 1:2 molar ratio.
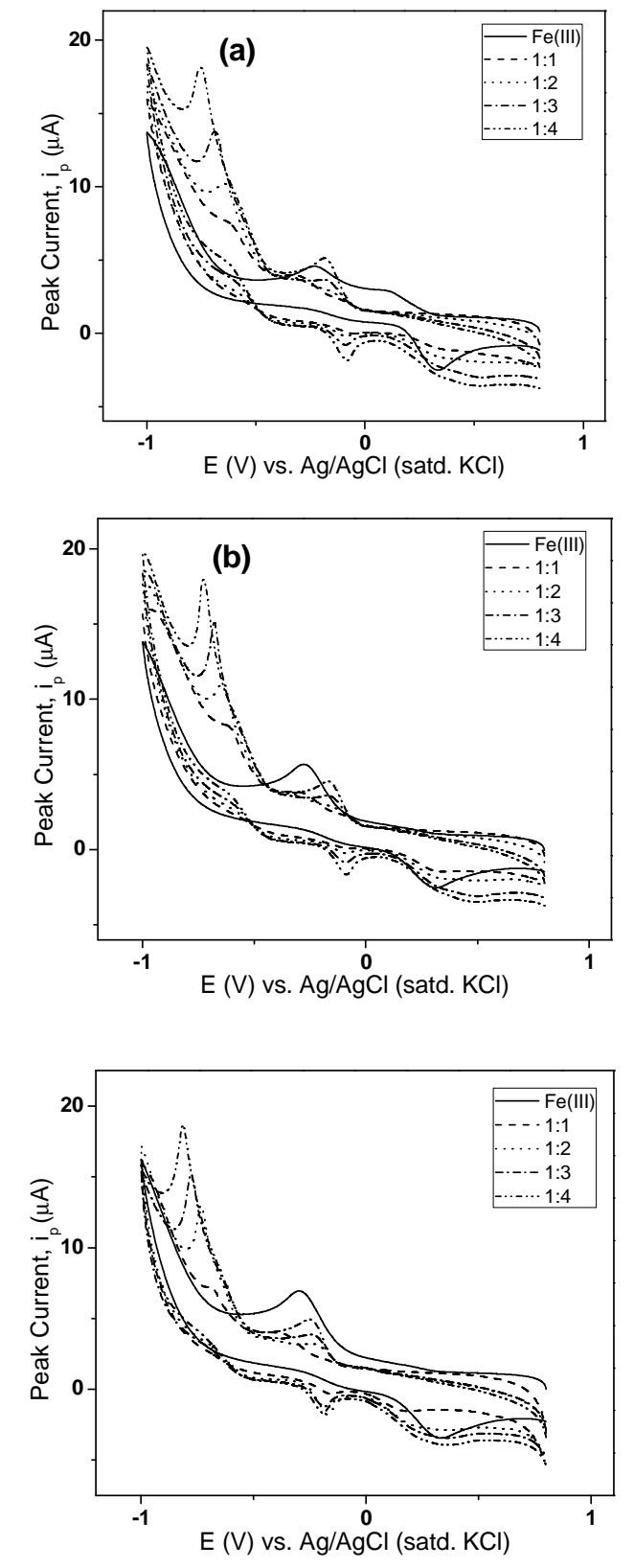

Fig. 7. $\mathrm{CVs}$ of $\mathrm{Fe}(\mathrm{III})$ (solid), and $\mathrm{Fe}(\mathrm{III}) / \mathrm{Rab}$ with different ratio (i) 1:1 (dot-dashed), (ii) 1:2 (dotted), (iii) 1:3 (long-dashed), and (iv) 1:4 (medium-dashed) in acetate buffer solution at (a) $\mathrm{pH} 3.5$, (b) $\mathrm{pH} 4.0$ and (c) $\mathrm{pH} 4.5$.

\section{Conclusion}

The cyclic voltammetric studies of the redox behavior of $\mathrm{Fe}(\mathrm{III})$ has been investigated in acetate buffer solution at various $\mathrm{pH}(\mathrm{pH} \mathrm{3.5,4.0}$ and 4.5) at GCE. CVs of Fe(III) showed a cathodic and an anodic peak in abovementioned $\mathrm{pH}$ and the redox couple $\mathrm{Fe}(\mathrm{III}) / \mathrm{Fe}(\mathrm{II})$ showed quasireversible behavior. Electrochemical studies on the interaction of $\mathrm{Fe}(\mathrm{III})$ with proton pump inhibitors (PPIs: omeprazole, pantoprazole, esomeprazole and rabeprozole) 
in acetate buffer were studied. In presence of omeprazole, the anodic and cathodic peak current for Fe(III) decreased than those of solely $\mathrm{Fe}(\mathrm{III})$. However, both the peaks were almost disappeared in some cases. Moreover, anodic and cathodic peaks were found to shift significantly towards the negative potential. Therefore, a strong interaction of $\mathrm{Fe}(\mathrm{III})$ and omeprazole was occurred. The maximum interaction was observed at the molar ratio of $1: 2$ between $\mathrm{Fe}(\mathrm{III})$ and omeprazole at $\mathrm{pH} 3.5,4.0$ and 4.5. Almost identical behavior was noticed for the electrochemical interaction of $\mathrm{Fe}(\mathrm{III})$ and other PPIs (pantoprazole, esomeprazole and rabeprazole). These results could guide us deep insight into the interactions of metal ions with the PPIs that were taken in human body quite regularly.

\section{Acknowledgement}

We are grateful to the Ministry of Education of Bangladesh for the financial support to complete the work.

\section{References}

1. Blume, H., F. Donath, A. Warnke, and B. S. Schug, 2006. Pharmacokinetic Drug Interaction Profiles of Proton Pump Inhibitors. Drug Safety 29, 769-784.

2. Horn, J. 2000. The proton-pump inhibitors: similarities and differences. Clin. Ther 22, 266-80.

3. Welage, L. S. and R. R. Berardi, 2000. Evaluation of omeprazole, lansoprazole, pantoprazole, and rabeprazole in the treatment of acid-related diseases. J. Am. Pharm. Assoc 40, 52-62.

4. Gerson, L. B. and G. Triadafilopoulos, 2001. Proton pump inhibitors and their drug interactions: an evidence-based approach. Eur. J. Gastroenterol Hepatol 13, 611-16.

5. McColl, K. E. 2009. Effect of proton pump inhibitors on vitamins and iron. Am. J. Gastroenterol 104, S5-S9.
6. Sheen, E. and G. Triadafilopoulos, 2011. Adverse effects of long-term proton pump inhibitor therapy. Dig. Dis. Sci 56, 931-950.

7. Zajac, P., A. Holbrook, M. E. Super and M. Vogt, 2013. An overview: Current clinical guidelines for the evaluation, diagnosis, treatment, and management of dyspepsia. Osteopath. Family Physician, 5, 79-85.

8. Dlouhy, A. C. and C. E. Outten, 2013. The iron metallome in eukaryotic organisms. In Metallomics and the Cell, L. Banci, Guest Ed.; Vol. 12 of "Metal Ions in Life Sciences," A. Sigel, H. Sigel, and R.K.O. Sigel, Series Eds.; Springer Science and Business Media B.V.: Dordhecht, Netherlands, 12, 241-78.

9. Finney, L. and T. O'Halloran, 2003. Transition metal speciation in the cell: insights from the chemistry of metal ion receptors. Science 300, 5621.

10. Golubov, J., P. Flanagan and P. Adams, 1991. Inhibition of iron absorption by omeprazole in rat model. Dig. Dis. Sci, 36, 405.

11. Frewin, R., A. Henson and D. Provan, 1997. ABC of clinical haematology. Iron deficiency anaemia. $B M J$ 314, 360.

12. Lee, Y.-C., E. Martin and F. Murad, 2000. Human recombinant soluble guanylyl cyclase: Expression, purification, and regulation. PNAS, 97, 10763.

13. Shaikh, A. A., S. N. Afzal, M. Q. Ehsan and A. H. Khan, 2005. Electrochemical study on redox reaction of iodine and bromine in presence of benzoylacetone at carbon electrodes. J. Saudi. Chem. Soc 9, 279-286.

14. Shaikh, A. A., M. Begum, A. H. Khan and M. Q. Ehsan, 2006. Cyclic voltammetric studies of the redox behavior of iron(III)-vitamin $\mathrm{B}_{6}$ complex at carbon paste electrode. Russ. J. Electrochem 42, 620-625. 
